\title{
Morphology of Root and C-Shape Canal in Prehispanic and Modern Maya Groups from Northern Yucatan
}

\author{
Andrea Cucina, ${ }^{1}$ Elma Vega Lizama, ${ }^{2}$ Marco Ramírez,${ }^{2}$ G. Alvarado Cárdenas, ${ }^{2}$ and Vera Tiesler ${ }^{1}$ \\ ${ }^{1}$ Facultad de Ciencias Antropológicas, Universidad Autónoma de Yucatán, Mérida, Yucatán, México; ${ }^{2} F a c u l t a d ~ d e$ \\ Odontología, Universidad Autónoma de Yucatán, Mérida, Yucatán, México
}

ABSTRACT One-rooted mandibular second molars are labelled "C-molar" because of the root's morphology. The frequency of C-molars is strongly associated with ethnic origin, being most common in North-East Asians. The present study analyzed the frequency of one-rooted molars and associated pulpal chamber in 48 Prehispanic Mayans and in 142 modern subjects studied at the School of Endodontics, UADY. The frequency of one-rooted molars in the Prehispanic sample is 35\%, with $32 \%$ of these having C-canals. Similarly, 42 of 142

The dental morphology of Maya populations belongs to the Sinodont family (Turner, 1990) and falls into the Sino-American group (Scott and Turner, 1997). It is characterized by, among other features, a high frequency of undivided roots in the lower second molar (Scott and Turner, 1997). Root morphology is one of the many traits commonly employed in dental studies of population affinities. Mandibular second molars are described according to a one- or two-roots dichotomy (with the very rare cases of three roots falling into the two-roots category) (Turner et al., 1991; Scott and Turner, 1997). The frequency of single rooted second lower molars in North and South American native populations has been reported to range between 30\% and 35\% (Scott and Turner 1997). Frequency of such traits in the Maya region ranges between $15 \%$ and $30 \%$ (Jacobi, 2000; Wrobel, 2004; Cucina et al., 2005).

From an endodontic perspective, single rooted lower second molars are described as C-shape, due to the pulp chamber morphology that appears as a " $\mathrm{C}$ " in the roots' cross section (see Jafarzaed and $\mathrm{Wu}, 2007$ for a review). Generally, the fused root is associated with the C-shape canal, even though the endodontic treatment that exposes the chamber cannot detect the actual morphology of the root.

The C-shape chamber morphology has been reported to be strongly associated with certain ethnic affiliations. High frequencies of C-shape second molars have been registered in Sinodont populations such as Chinese, Japanese and Koreans, while being relatively uncommon in Caucasoid or African peoples (Yang et al., 1988; Habbad et al., 1999; Gulabivala et al., 2001; Seo and Park, 2004; Jin et al., 2006; Jafarzaed and Wu, 2007). The
(30\%) modern teeth exhibit a C-canal. The similarity between ancient and modern samples suggests that genetic admixture since the European conquest has not affected trait expression, and it implies that the Maya express the Sinodontic pattern of dental morphology. Endodontically, the significant correlation between C-molar and C-canal is an advantage for recognizing the canal's anatomy if treatment is indicated. Dental Anthropology 2008;21(2):46-49.

Maya population's ancestry is Sinodont, yet the conquest has led to admixture with European and African populations in the region, likely altering the genetic (and morphological) structure of the population.

The goal of the present study is twofold: firstly, it aims at inferring the frequency of C-shape second molars in the Maya populations according to their ancestry in order to assess the continuity or discontinuity in the prevalence of this trait in the region in an evolutionary perspective; secondly, the actual correlation between root and canal form is measured in order to infer to what extent the single root (as a morphological trait) corresponds to a C-shape canal in its inner structure.

\section{MATERIALS AND METHODS}

The archeological sample consists of 48 mandibular second molars dated to the Classic period (250-800 AD), recovered from Xcambó and Noh Bec in northern Yucatán. They were selected randomly (Fig. 1); in most of the cases, the bony structure was missing or partly destroyed, so that the tooth had fallen out naturally. No tooth was extracted from its socket, since single rooted molars can be removed more easily than two-rooted ones, introducing a bias in its frequency. The one-rooted molars were then X-rayed to assess the shape of the

Correspondence to: Andrea Cucina, Facultad de Ciencias Antropológicas, Universidad Autónoma de Yucatán, Mérida, Km. 1 Carretera Mérida-Tizimín, 97305 Mérida, Yucatán, México

E-mail: acucina@yahoo.com 
canal (Fig. 2). No archeological tooth was sectioned or partially destroyed to inspect the morphology of the inner chamber on ethical and legal grounds, as destructive analysis of archeological materials requires the permission of the Archeology Council under Mexican law. Once scrutinized, the teeth were returned to their own individual's storage boxes.

The modern sample consists of 142 second lower molars. It was registered by one of the authors (EVL) on patients attending the School of Endodontics of the Universidad Autónoma de Yucatán (UADY) for treatment during the fall semester of 2007. In this dental series, the form of the canal could be assessed visually from the occlusal surface (Fig. 3). X-rays were performed for every subject to provide additional information on the root morphology, even though this set of data could not be used directly in the present study.

Patients receiving treatment at the School of Endodontics of the UADY usually come from low income sectors of society. Relying on the subject's patient records, they are all of native origin and even though most of them were born in the town, their parents commonly originated in villages in northern Yucatán. Despite admixture, which makes any direct comparison to Prehispanic series problematic, this sample is largely representative of the natives' genetic background.

\section{RESULTS}

Among the 48 archeological roots under study, 17 were fused, constituting $35 \%$ of the total. Radiographic analysis revealed that 15 out of 16 individuals possessed a C-shape morphology in at least some parts of their root canal. One tooth was excluded because the X-ray did not permit inspection of the form of its chamber. The resulting ratio corresponds to $32 \%$ of the overall sample (15/47). The modern cohort represents a $29 \%$ of second lower molars with a C-shape canal (42/142). The difference between the archeological and modern sample is not significant (chi-square $=0.014 ; \mathrm{P}=0.905$ ) (Table 1). As mentioned, no reliable information is available on the frequency of the one-rooted molar in the modern sample. We can assume that at least 42 out of 142 teeth were single-rooted; however, we cannot rule out the possibility that not all the one-rooted molars presented the C-shape. At the same time, two partly fused roots (forming a C-shape canal) may diverge towards the apical end. In anthropological terms, when the root is separated for at least one third of its length, it is considered as two roots.

\section{DISCUSSION}

Genetic admixture (gene flow) is one of the reasons for changes in trait frequencies, and dental attributes are no exception. In opposition to other populations, like the Caribbean Tainos, who suffered a profound demographic collapse that led to its extinction within

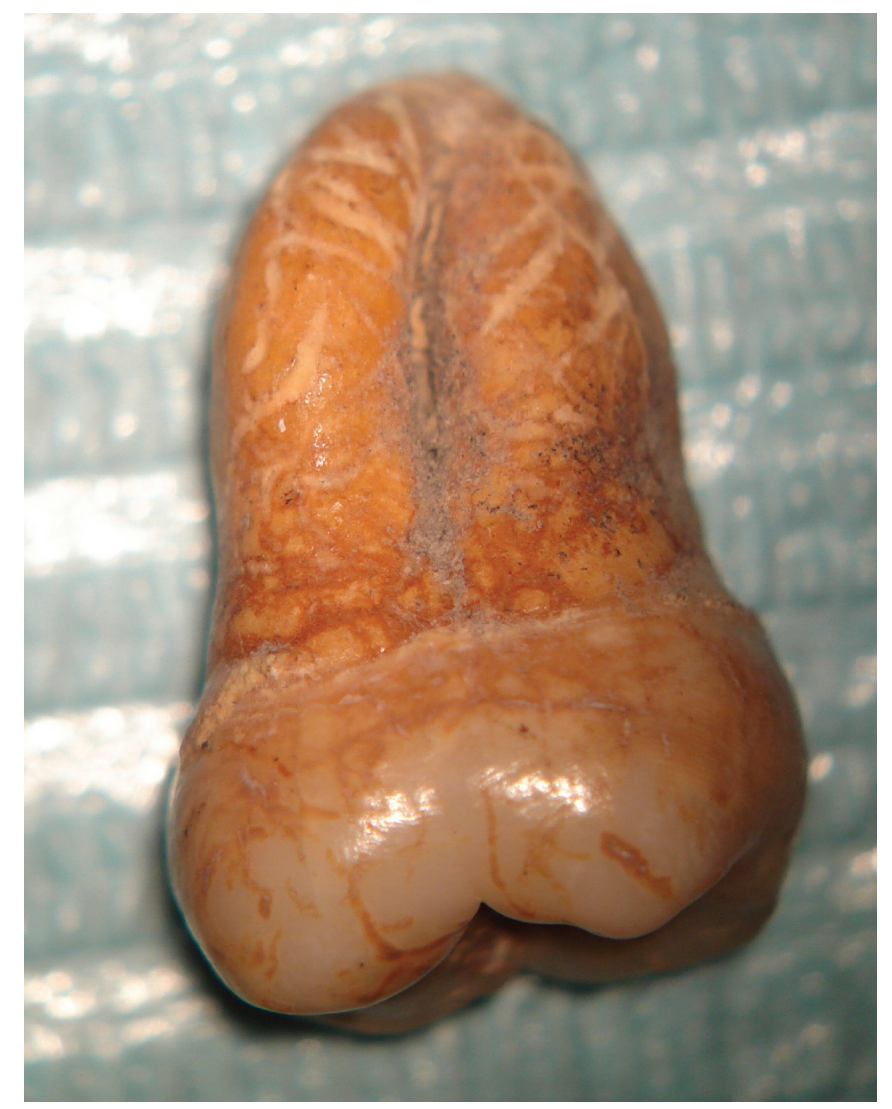

Fig. 1. Archeological example of a second mandibular molar from northern Yucatan, dated to the Classic period, which may possess a C-canal.

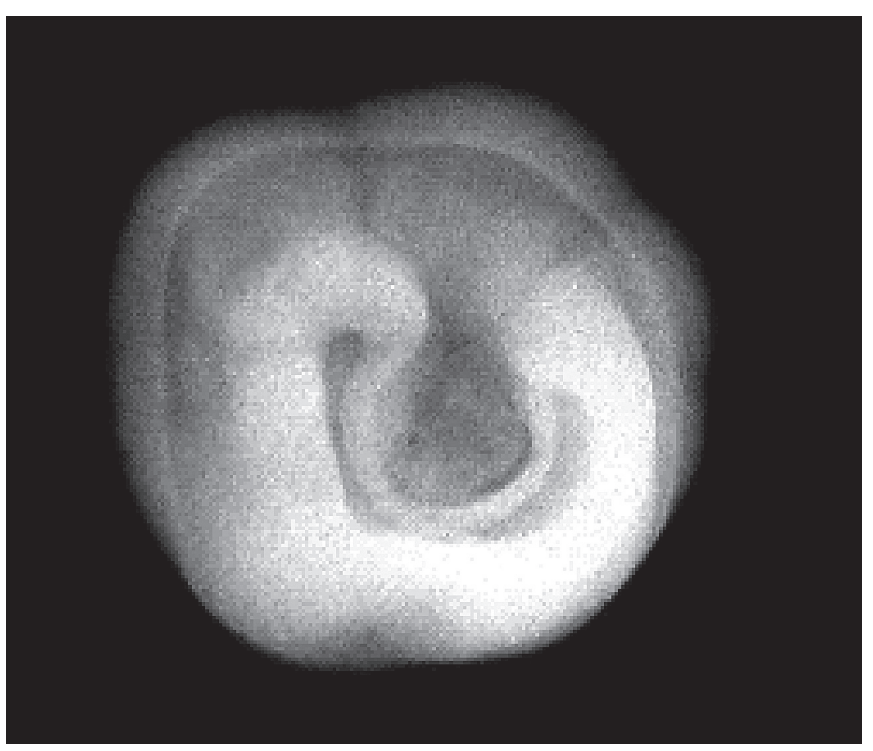

Fig. 2. X-ray image of the pulp chamber in an archeological second mandibular molar. The C-shape canal can be appreciated from the apical surface. 
TABLE 1. Counts and frequencies of C-shape canals and single-rooted second mandibular molars

\begin{tabular}{lccccc}
\hline Sample & Total & One-root & $\begin{array}{c}\text { Frequency } \\
\text { One-root }\end{array}$ & $\begin{array}{c}\text { C-shape } \\
\text { Count }\end{array}$ & $\begin{array}{c}\text { C-shape } \\
\text { Frequency }\end{array}$ \\
\hline Prehispanic & 48 & 17 & $35.4 \%$ & 15 & $31.9 \%^{\dagger}$ \\
Modern & 142 & $? ?$ & $? ?$ & 42 & $29.4 \%$ \\
\hline
\end{tabular}

${ }^{\dagger}$ One single-rooted molar could not be scored for canal form.

few decades after the conquest (Rouse, 1963; Moya-Pons, 1982), the Maya became an integrated part of the newly formed, multi-ethnic society. The genetic admixture that occurred in Yucatan as a natural consequence of the European conquest and introduction of African slaves surely had an impact in the gene pool in the region. Here, demic movement also could have led to noticeable changes in the patterns of dental morphology. Jacobi (2000) reported that the greater morphological distance between historic Tipu and Historic Lamanai in Belize was likely the consequence of a major admixture of Mayas from northern Yucatán fleeing to Lamanai.

The present study has centered on just two traits. Clearly, it will be necessary to inspect a broader set of dental morphological traits in order to assess the extent to which admixture and time have modified the genetic structure of the modern Maya population compared to their Prehispanic status. This will be the goal of future studies.

Single-rooted second mandibular molars are very common in Maya populations, slightly less common in Europeans, and they appear to be rare in Africans (Scott and Turner, 1997). Since the frequency of fused

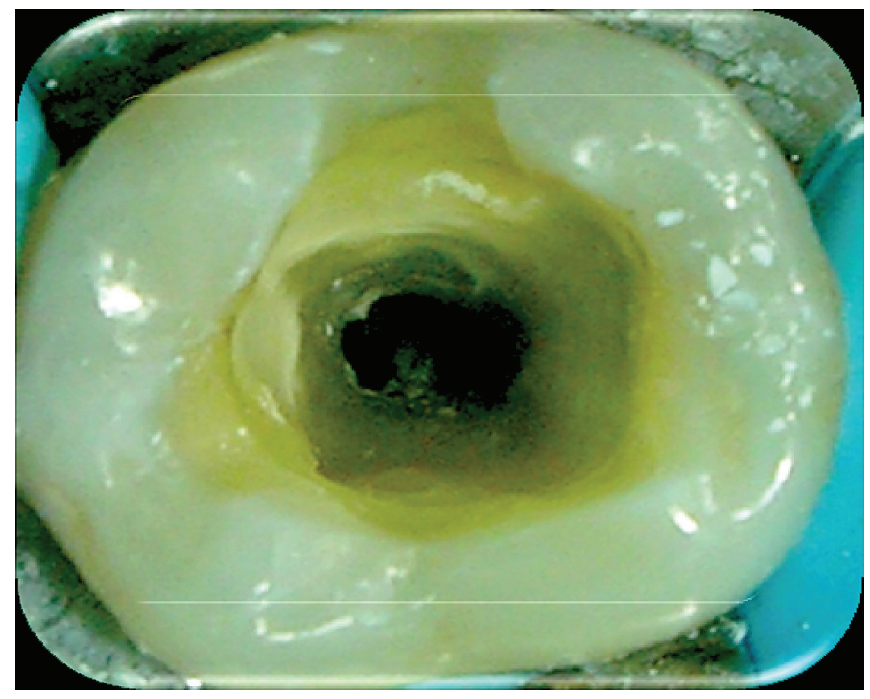

Fig. 3. Occlusal view of a C-shape root canal in a modern patient before being treated at the School of Endodontics, UADY. Mesial is to the right of the picture, and buccal is to the top. roots in European groups is slightly lower than in Mesoamerican ones, admixture might not have led to profound changes in the modern sample. The frequency is very much lower in Africans (Scott and Turner, 1997). Specifically for sub-Saharan regions, from which the initial forced migration into the New World started in the 16th century AD, Irish (1997) reported a value of $7 \%$. Even though African populations are considered to be the third root of the modern Mexican population (Tiesler et al., 2008), their genetic contribution may not have been large enough to produce noticeable changes, at least not in the Yucatan region that has experienced a lower presence of African descendents than in neighboring states.

Conversely, the distribution in canal shapes differs significantly between the Maya and Old World groups (Europe and Africa). C-shape root canals appear at comparable frequencies in the modern and Prehispanic Yucatecan population, while being uncommon in Old World groups (Jafarzaed and Wu, 2007). As a result of admixture, we were initially expecting a reduced frequency of " $\mathrm{C}$ " canals in the modern sample when comparing it to the Prehispanic series. It is puzzling, instead, that the frequencies are very much alike.

The form of the root canal is listed among dental anatomical anomalies (Jerome and Hanlon, 2007) and, at least until now, it does not seem to have specific evolutionary implications like other morphological traits that have been associated with dental reduction. Yet, the persistence of single-rooted second molars and, notably, the C-shape pulpal chamber in the modern series under study might indicate a genetic (or morphological) stability of this feature. Even though we stress the fact that a single trait is not sufficient to assess the extent of admixture, the persistence of this feature can be indicative of a persistent homogeneous composition of the modern Maya population in northern Yucatan.

Muchremainstobedone. Fromajointanthropological and clinical perspective, the strong correlation between root form and canal morphology in the Prehispanic sample might be instrumental in understanding the occurrence of these traits in modern populations. The endodontic literature (see Jafarzaed and Wu's review, 2007) does not report the ethnic affiliation of those samples with low occurrence of C-shape canal. Given the extensive information on the C-shape canal in Asian peoples and the relative paucity in the other continents, 
further studies will shed light on this trait within the broader Mesoamerican sphere and in European and African groups.

\section{ACKNOWLEDGEMENTS}

We are grateful to Thelma Sierra Sosa, Xcambó Archaeological Project, and Agustín Peña Castillo, Noh Bec/El Escondidio Archaeological Project, for the archeological materials scrutinized in this study.

\section{LITERATURE CITED}

Cucina A, Tiesler V, Wrobel G. 2005. Afinidades biológicas y dinámicas poblacionales mayas desde el Clásico hasta el periodo colonial. Los Investigadores de la Cultura Maya 13: 559-567.

Gulabivala K, Aung TH., Alavi A, Ng YL. 2001. Root and canal morphology of Burmese mandibular molars. Int Endod J 34:359-370.

Haddad GY, Nehme WB., Ounsi HF. 1999. Diagnosis, classification and frequency of C-shape canals in mandibular second molars in the Lebanese population. J Endod 25:268-271.

Irish JD. 1997. Characteristic high- and low-frequency dental traits in sub-Saharan African populations. Am J Phys Anthropol 102:455-467.

Jabobi K. 2000. Last rites for the Tipu Maya: genetic structuring in a Colonial cemetery. Tuscaloosa: University of Alabama Press.

Jafarzadeh H, Wu YN. 2007. The C-shaped root canal configuration: a review. J Endodont 33:517-523.

Jerome CE, Hanlon RJ. 2007 Dental anatomical anomalies in Asians and Pacific islanders. CDA Journal 35:631636.

Jin GC, Lee SJ, Roh BD. 2006. Anatomical study of Cshape canals in mandibular second molars by analysis of computed tomography. J Endodont 32:10-13.
Moya-Pons F. 1982. Los trabajadores indígenas y la estructura social en La Española en 1514. Boletín del Museo del Hombre Dominicano 17:119-133.

Rouse I. 1963. The Arawak. In: Steward JH, editor. Handbook of South American Indians. Vol 4. New Cork: Copper Square Publishers, p 507-546.

Scott GR, Turner CG II. 1997. The anthropology of modern human teeth. Cambridge: Cambridge University Press.

Seo MS, Park DS. 2004. C-shape root canals of mandibular second molars in a Korean population: clinical observation and in vitro analysis. Int Endod J 37:139-144.

Tiesler V, Zabala P, Cucina A, editors. 2008. Encounters at the Edge of the Sea. European, Maya and African Founders of Campeche, Mexico. Gainesville: University Press of Florida.

Turner CG II. 1990. Major features of Sundadonty and Sinodonty, including suggestions about East Asian microevolution, population history and Late Pleistocene relationships with Australian aboriginals. Am J Phys Anthropol 82:295-317.

Turner CG II, Nichol CR, Scott GR. 1991. Scoring procedures for key morphological traits of the permanent dentition: the Arizona State University dental anthropology system. In: Kelley MA, Larsen CS, editors. Advances in dental anthropology. New York: Wiley-Liss, p 13-31.

Yang ZP, Yang SF, Lin YC, Shay JC, Chi CY. 1988. C-shape root canals in mandibular second molars in a Chinese population. Endod Dent Traumatol 4:160-163.

Wrobel GD. 2004. Metric and non-metric dental variation among the ancient Maya of Northern Belize. Ph.D. dissertation, University of Indiana, Indiana. 